This item was submitted to Loughborough's Research Repository by the author.

Items in Figshare are protected by copyright, with all rights reserved, unless otherwise indicated.

\title{
Studies of the characteristics of brand names used in the marketing of information products and services II: Internet related services
}

PLEASE CITE THE PUBLISHED VERSION

PUBLISHER

Emerald / @ Professor Oppenheim

LICENCE

CC BY-NC-ND 4.0

\section{REPOSITORY RECORD}

Angus, Emma, and Charles Oppenheim. 2019. "Studies of the Characteristics of Brand Names Used in the Marketing of Information Products and Services II: Internet Related Services". figshare.

https://hdl.handle.net/2134/277. 


\title{
C Loughborough
}

This article has been submitted to Loughborough University's Institutional Repository by the author.

\section{Studies of the characteristics of brand names used in the marketing of information products and services II: Internet related services ${ }^{1}$}

\author{
Emma Angus and Charles Oppenheim* \\ Department of Information Science \\ Loughborough University, \\ Leics LE11 3TU
}

\section{Introduction}

In commercial and industrial markets, the necessary distinctiveness is often achieved by packaging and labelling. These have often been the subject of intensive research with the aim of improving the naming, presentation, differentiation and promotion of individual products or services (Myers et al., 1979).

With regards to Internet information services, distinctiveness can also be achieved through the use of brand names. Their use raises the question: what characteristics of brand names allow users to distinguish the information services which will be of most value to them?

Rowley defines a brand (Rowley, 1997) as,

A name, term, sign, symbol or design, or a combination of them, intended to identify the goods or services of one seller or group of sellers and to differentiate them from those of the competitors

\footnotetext{
${ }^{1}$ Part I of this series is (Myers, Oppenheim, \& Rogers, 1979).
} 
Rowley has also examined the messages and values that brand names and branding strategies can communicate to users (Rowley, 2003). She put forward some examples of existing brands and the messages they convey,

Disney uses the Mickey Mouse logo for recognition, and a style that communicates 'magic'. Boots uses the website address 'wellbeing.com' to communicate that they want to be seen as working with their customers on their health.

However, she also points out that, 'branding in online environments is not easy; there is not much scope for getting messages across through that first screen.'.

Chan and Huang state that,

The ultimate goal of branding is to promote products and services, so that potential consumers will have their interests and needs aroused, and ultimately their purchase decision will be taken. (Chan \& Huang, 1997)

As in commercial and industrial markets, distinctiveness between products is achieved by branding or trade marks and by packaging and labelling. Although there is a general acceptance that there are several overlaps when it comes to the branding of physical goods and services, services are generally perceived as being more difficult to brand (Blankson \& Kalafatis, 1999)

Robertson (Robertson, 1992) carried out extensive research into strategically desirable brand name characteristics and suggested that there are two basic dimensions upon which the strategic desirability of a brand name should be judged: (1) the inherent ability of the name to be easily encoded into, retained in, and retrieved from memory; and (2) the extent to which the name supports or enhances the planned strategic positioning or image of the product. Robertson concluded that managers who are attempting to select a 'successful' brand name for a product, service or company should be guided by nine basic principles;

1. The brand name should be a simple word.

2. The brand name should be a distinctive word.

3. The brand name should be a meaningful word. 
4. The brand name should be a verbal or sound associate of the product class.

5. The brand name should elicit a mental image.

6. The brand name should be an emotional word.

7. The brand name should make use of the repetitive sounds generated by alliteration, assonance, consonance, rhyme and rhythm.

8. The brand name should make use of morphemes.

9. The brand name should make use of phonemes

A morpheme was defined as, 'the smallest linguistic unit having consistent meaning....this ranges from full words, to small parts of words such as the ending "-ly", including prefixes, suffixes and roots.' Phonemes are classed as, 'linguistic units smaller in size than morphemes, such as individual letter sounds.'

There are a number of studies, which have investigated some of the principles put forward by Robertson. Bellezza and Apel carried out research into the effects of imagery and pleasantness on recalling brand names (Bellezza \& Apel, 2001). They tested two hypotheses in their research. One hypothesis was that the visual imagery associated with a brand name influences its recall. The second hypothesis was that the pleasantness of the brand name may also influence its recallability. They found that both high imagery and high pleasantness brand names were recalled better than low imagery and low pleasantness brand names.

Vanden Bergh conducted a study to determine if, 'brand names that begin with consonants called "plosives” (B,C, D,G, K, P and T) are more readily recalled and recognised than names that begin with other consonants or vowels.' (Vanden Bergh, 1984). Additionally, the study investigated the relationship between name length and memorability, ability to associate names with other things, and ability to recall and recognise names. Vanden Bergh found that brand names using plosives were recalled much more than non plosives, and that as word length increased (i.e., number of syllables), recall and recognition decreased. In conclusion, the experimenters recognised that, 
although memorablity is not the only goal in the brand name selection process, the apparent effect of the type of sound selected to begin a name with is an important variable to consider in choosing names that must compete against the clutter of the marketplace for a spot in consumers' minds.

In contradiction to Vanden Bergh’s study, Bellezza and Apel suggest that,

if less meaningful linguistic units such as nonsense syllables are used, people have little basis for making ratings of imagery and pleasantness, and are therefore less likely to recall the words.(Bellezza \& Apel, 2001)

Research which has looked more specifically at the development of brand names for information services tends to draw upon a range of different marketing techniques in order to create a framework for successful branding. Moorthi (Moorthi, 2002) presents an approach for branding services by applying a brand identity framework, (i.e., brand as product, organisation, person and symbol) to the economic classification of three types of goods, (i.e., search, experience and credence goods) and the 7P's of services marketing (i.e., product, price, place, promotion, physical evidence, process and people).

Moorthi created a new branding model, (see Figure 1.)

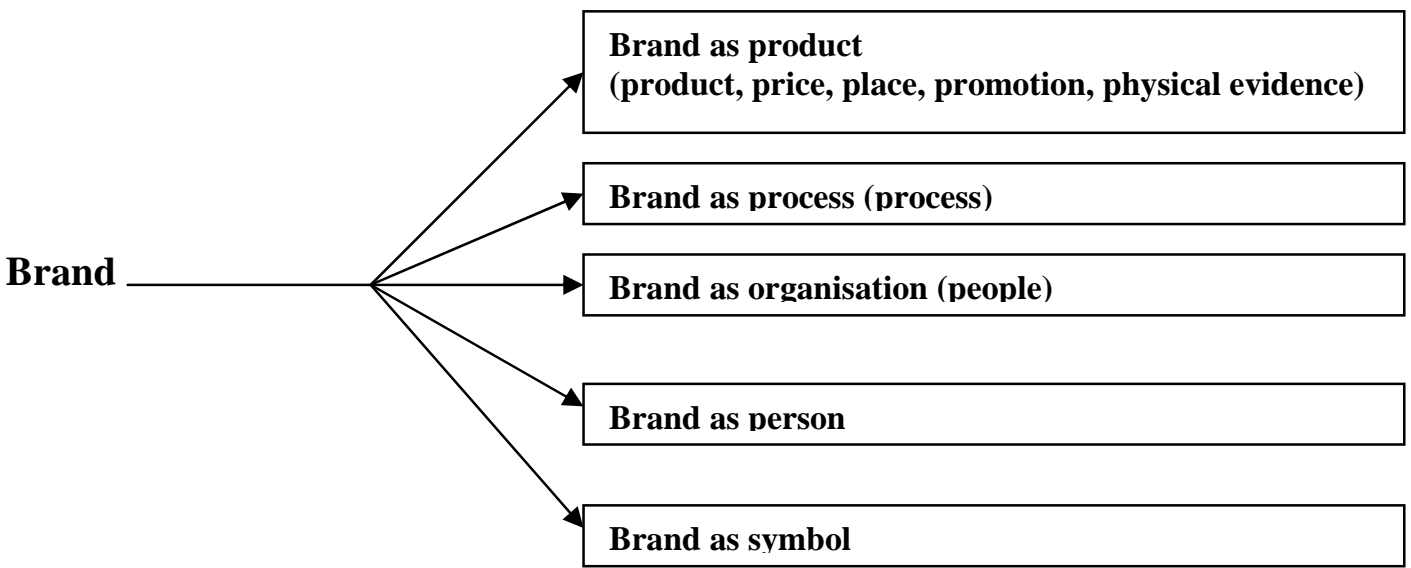

Figure 1. Proposed services branding model

From this proposed framework, Moorthi places special emphasis on both 'brand as person' and 'brand as symbol' in relation to branding services. In terms of online information services, the 'person' in the branding framework becomes the service provider. This service provider needs to take on the role of a 'personality' and become a 
'friend' to the user. When a user of an online information service begins to encounter difficulties or problems, they need to know that the service they are using is 'user friendly’ enough in order that they may overcome their search difficulties.

Moorthi points out that in creating the proposed services branding model, a basic initial attempt at conceptualising the branding of a service can be achieved. It is pointed out however that the framework has limitations in that, 'if the service brand under consideration is a multi product brand or a corporate brand, this approach cannot be used directly.'

An interesting point to consider when designing brand names which are aimed at an international level is that of a universal language. Chan and Huang conducted a linguistic investigation of over 500 Chinese brand names, 'analysing the phonetic features, morphological structures and semantic interpretations which are the linguistic foundation guiding brand naming in China.'(Chan \& Huang, 1997)

For products targeting primarily the local market, the branding task is relatively simple because only the linguistic features of that language and the preference of the consumers in the community concerned need to be considered. To brand a product for the international market, consideration of the linguistic universals, i.e. the linguistic traits which occur in all or most human languages, has to be taken into account.

They point out how languages can differ in syllable structure. For example, in contrast to English, the Chinese have a very simple syllable structure and they do not allow consonant clusters.

In 1979, Myers et al carried out a study (Part I of this series of articles) which looked at the characteristics of brand names used in marketing information products and services (Myers et al., 1979). they explored the characteristics of 218 brand names associated with microfilm/microfiche readers, computerised information retrieval systems and online databases. The brand names were analysed for the product information they conveyed and for the characteristics of the words employed. 
They found that the brand names studied tended to employ meaningless concocted words and that the favoured words began and ended with a consonant. Both computerised information systems and online databases tended to employ nouns far more than adjectives; in contrast, microfilm readers were far more likely to employ brand names which conveyed product information or atmosphere.

Turley and Moore looked specifically at brand name strategies within the service sector. They put forward two basic purposes which they were aiming to achieve (Turley \& Moore, 1995). First, they described a classification system which describes broad alternative brand name strategies for services. They then presented data which explores the degree to which these strategies are used by existing service firms, as well as the degree to which these strategies vary between different types of service. In order to obtain their data, the authors evaluated television commercials which advertised services and/or service firms and noted their service classification and their brand strategy selection. The authors suggest that,

\begin{abstract}
Brand managers in the service sector face some problems which are distinct from those of their colleagues in product marketing. Services, probably due to their inherent intangibility, provide consumers with fewer cues, which makes their evaluation process more difficult. In some cases, the brand name, the price, and the facility or "factory" may be the only cues available to the consumer prior to purchasing the service. When coupled with the increasing competitive environment, this lack of information in services tends to make the purchasing of a service a high risk proposition for consumers.
\end{abstract}

Turley and Moore also highlighted the fact that service brand names tend to be longer than those of product brand names (several words is often the norm).

Bergstrom pointed out (Bergstrom, 2000) that:

As internet usage grows, brands are becoming even more important than they have been in other channels or environments. With more choices from many unknown providers, customers tend to choose a provider that represents a set of values or attributes that are meaningful, clear, and trusted (a brand).

In view of the dramatic growth of new brands in the electronic information industry, including subject based gateways and search engines with innovative names (e.g., SOSIG and Google), it is surprising that no study has been carried out on the brand 
names used in electronic information services since Myers' et al's pioneering work a quarter of a century ago.

\section{Methods Adopted}

A list of 100-300 brand names for each of three categories of information service were obtained. 601 brand names were obtained in total. The names were acquired from standard reference sources:

- search engines (using search engine watch ${ }^{2}$ and Google ${ }^{3}$ )

- online databases (using Gale’s database directory (Faerber, 2002))

- subject gateways/portals (using $\mathrm{JISC}^{4}$ and the RDN service ${ }^{5}$ )

For online databases, the brand names were picked at random (one name being taken out of every twenty). All of the brand names which could be obtained for the other services were included in the analysis. A list of the service names used is obtainable from the senior author.

The analysis itself took the form of two separate approaches, which were later linked together. The first approach was an individual analysis, and the second was a questionnaire. The reason for adopting two separate approaches to the analysis was in order to be able to cross reference both objective and subjective data. Much of the research described in the literature review involves the authors putting forward recommendations for the most desirable brand name characteristics, based on the views and preferences of a sample of people included in an experiment. The characteristics suggested might therefore be subjective. It is difficult for any one person to objectively judge whether or not these characteristics would be the most successful for brand names.

\footnotetext{
${ }^{2}$ Search Links. < http://www.searchenginewatch.com>, [accessed 19.11.02].

${ }^{3}$ Google. <http://www.google.co.uk $>$, [accessed 19.11.02].

${ }^{4}$ JISC. $<$ http://www.jisc.ac.uk $>, 2002$, [accessed 19.11.02].

${ }^{5}$ RDN browse. < http://www.rdn.ac.uk>, 1999-2001, [accessed 19.11.02].
} 


\section{Analysis of Brand Names}

The linguistic characteristics of the brand names were analysed. Words can be analysed in four main ways (Chan \& Huang, 1997):

1. Syllable structure

2. Semantic structure

3. Morphological structure

4. Phonetic structure

Syllable structure refers to the construction of a word and the pattern of vowels and consonants. For the purposes of this analysis, the semantic structure of the brand names was examined in terms of the information which the name conveyed and whether this was direct or indirect. Semantic structure was also examined in terms of word class, (e.g., was the word a noun/verb adjective, etc) and whether or not the word was an existing word or was concocted. Distinctive linguistic characteristics, such as alliteration, assonance and consonance were also considered.

For the purposes of this analysis, the morphological structure looked at how many words encompassed the overall brand name and how many letters this was in total.

The phonetic structure of a word relates to how the word actually sounds when pronounced, (i.e., the use of plosives).

We therefore decided that the brand names would be analysed against the following criteria:

The service information they convey

- Does the brand convey information about the service or not?

- Is any information which is conveyed given directly or indirectly?

Characteristics of the words employed 
- Is the brand name an existing word or a concocted term?

- Does the brand name make use of alliteration, assonance or consonance?

- How long is the brand name? (i.e., number of letters)

- What is the pattern of vowels and consonants?

- Does the brand name make use of plosives?

For each of the six criteria, the most frequently occurring characteristic was noted. These characteristics were compared across each of the three information services to establish if there were any patterns or similarities.

\section{Designing the questionnaire}

The results obtained then formed the basis for three questionnaires, one for each of the information services looked at. The questionnaires were designed to test whether or not those characteristics which occurred most frequently in the list of brand names obtained, were indeed the characteristics which are preferred by people who are using information services.

Each questionnaire was split into six sections, one for each of the six categories of criteria which the brand names were analysed against. Each of the six sections contained two genuine brand names. One employed the most frequently occurring characteristic for that specific category, and one did not employ this characteristic. As genuine brand names were used, unfamiliar ones were used to try to stop participants only picking brand names which they had heard or used before. For each section, respondents were asked to pick one out of the two possible brand names they were most likely to use if they were searching electronic sources.

As the nature of the research was looking at people who were familiar with using online information services, it was decided that a cluster sample of Loughborough University DIS (Department of Information Science) staff and students would be used. People based in this Department are familiar with using online information services. 
Participants were randomly allocated to be sent only one of the three possible questionnaires.

The three questionnaires were distributed by email to 530 DIS staff and students. The questionnaires were sent out in late January 2003.

Responses from the questionnaires were analysed using the non-parametric Chi-squared test to determine which brand names people preferred the most. The results were then correlated with the results from the brand name analysis in order to determine their significance and to see if any patterns or similarities emerged.

\section{Results}

The overall results are summarised below in Tables 1, 2 and 3 and 4 below: 
Table 1. Brand name characteristics

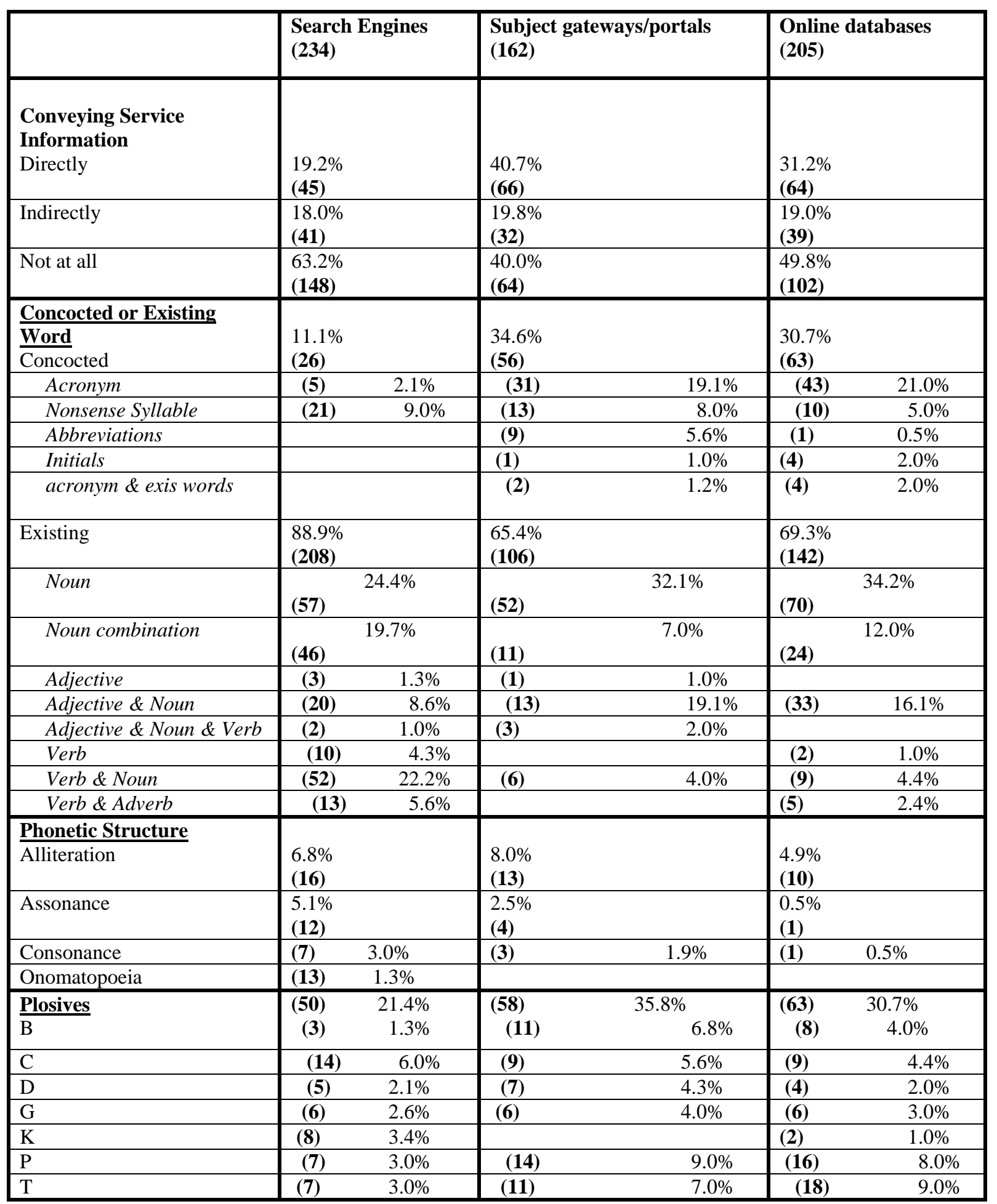


Search engines tended to convey far less service information than both online databases and subject gateways/portals. One possible reason for this, is that both online databases and gateway/portals are generally related to one specific subject (e.g., MEDIC - medical database / The Scientific World - science portal.), whereas search engines look for information on a multitude of different subjects. The service information results were then analysed using the Chi-squared test. It was found that the differences between the three classes of service were significant $(p \leq 0.001)$.

There is an obvious difficulty in deciding which word class a particular word falls into, as words can change meaning depending on the context they are used in. For the purpose of this analysis, it was decided that words would be analysed in the context in which they were being used as part of the brand name. From this, it was found that all three service categories used existing names for their brand names far more than concocted words, with nouns being the most popular word class. However, search engines did tend to adopt a far higher proportion of verb combinations than the other two service categories. A possible reason for this, being that search engines look for information after a key word has been entered into the search box, this in itself creates an 'action', and is reflected in brand names such as, 'Search66', 'Surf 2 it' 'Surf N Search'. It was found that these differences were also significant $(p \leq 0.001)$.

It was also noted that the brand names of both subject gateways/portals and online databases consisted of a far higher proportion of acronyms than that of search engine brand names. This difference is possibly a further reflection of the fact that subject gateways and databases are generally related to one specific subject. Specific subject areas which are very precise in nature may sound rather long winded or not particularly catchy when used as a brand name. Acronyms are often created in order to encompass the first letters for each of the words included in the subject title, (e.g., SOSIG - Social Science Information Gateway / RUDI - Research for Urban Design Information).

Phonetic structure, (the use of alliteration, assonance, consonance, and onomatopoeia) was not a predominant feature for any of the service categories. This indicates that these 
features were only used if the information service explicitly lent itself to one of these techniques at the brand creation stage, rather than the brand being created to fit around the information service as part of a branding strategy. This point was again true for the use of plosives. However, the differences between the three groups were not statistically significant.

\begin{tabular}{|c|c|c|c|c|c|c|}
\hline Number of letters & \multicolumn{2}{|c|}{ Search Engines } & \multicolumn{2}{|c|}{ Subject Gateways/portals } & \multicolumn{2}{|c|}{ Online Databases } \\
\hline 3 & $1.0 \%$ & (2) & $2.0 \%$ & (3) & $2.0 \%$ & (4) \\
\hline 4 & $1.3 \%$ & (3) & $13.0 \%$ & (21) & $6.0 \%$ & (12) \\
\hline 5 & $4.7 \%$ & (11) & $7.4 \%$ & (12) & $7.3 \%$ & (15) \\
\hline 6 & $8.6 \%$ & (20) & $6.8 \%$ & (11) & $7.3 \%$ & (15) \\
\hline 7 & $9.0 \%$ & (21) & $9.3 \%$ & (15) & $10.7 \%$ & (22) \\
\hline 8 & $10.3 \%$ & (24) & $5.6 \%$ & (9) & $8.8 \%$ & (18) \\
\hline 9 & $13.0 \%$ & (30) & $3.1 \%$ & (5) & $6.8 \%$ & (14) \\
\hline 10 & $8.6 \%$ & (20) & $1.9 \%$ & (3) & $7.3 \%$ & (15) \\
\hline 11 & $10.3 \%$ & (24) & $3.1 \%$ & (5) & $5.0 \%$ & (10) \\
\hline 12 & $5.1 \%$ & (12) & $1.9 \%$ & (3) & $3.0 \%$ & (6) \\
\hline 13 & $5.1 \%$ & (12) & $1.9 \%$ & (3) & $4.0 \%$ & (8) \\
\hline 14 & $4.0 \%$ & (9) & $5.0 \%$ & (8) & $4.0 \%$ & (8) \\
\hline 15 & $3.4 \%$ & (8) & $2.5 \%$ & (4) & $2.4 \%$ & (5) \\
\hline 16 & $1.7 \%$ & (4) & $1.9 \%$ & (3) & $1.5 \%$ & (3) \\
\hline 17 & $2.1 \%$ & (5) & $3.1 \%$ & (5) & $2.4 \%$ & (5) \\
\hline 18 & $1.3 \%$ & (3) & $5.0 \%$ & (8) & $3.0 \%$ & (6) \\
\hline 19 & $1.3 \%$ & (3) & $1.9 \%$ & (3) & $2.0 \%$ & (4) \\
\hline 20 & $1.3 \%$ & (3) & $1.2 \%$ & (2) & $1.0 \%$ & (2) \\
\hline $21+$ & $3.1 \%$ & (19) & $14.9 \%$ & (39) & $8.3 \%$ & (33) \\
\hline
\end{tabular}

Table 2. Word Lengths of Brand Names (if a name comprised of more than one word, the letters were added together and treated as one)

\begin{tabular}{|l|l|l|l|}
\hline $\begin{array}{l}\text { Average Word } \\
\text { Lengths }\end{array}$ & Search Engines & Subject Gateways/portals & Online Databases \\
\hline Mean & 7.8 & 4.4 & 6.2 \\
\hline Mode & 9 & 4 & 7 \\
\hline Median & 17.5 & 21 & 19 \\
\hline Standard Deviation & 8.6 & 4.4 & 5.7 \\
\hline
\end{tabular}

Table 3. Average Word Lengths

Overall, subject gateways/portals had a higher proportion of brand names consisting of 21 or more letters, yet the mode word length for this category was four letters, which was lower than that of the other two categories. Nine letters was the most popular length 
for search engines, and seven for online databases. These differences between the three types of service were significant $(\mathrm{p} \leq 0.001)$.

Analysis of the syllable structure of brand names showed that a consonant-consonant pattern was consistently the most popular pattern found across all three service categories. However, this merely reflects the structure of the English language, where the largest proportion of words both begin and end in a consonant (Chan \& Huang, 1997).

\begin{tabular}{|l|lr|lr|lr|}
\hline & \multicolumn{2}{|l|}{ Search Engines } & \multicolumn{2}{|c|}{ Subject gateways/portals } & \multicolumn{2}{|c|}{ Online Databases } \\
\hline $\mathrm{A}-\mathrm{A}$ & $7.6 \%$ & $\mathbf{( 3 7 )}$ & $7.2 \%$ & $\mathbf{( 2 8 )}$ & $9.3 \%$ & $\mathbf{( 3 9 )}$ \\
\hline $\mathrm{A}-\mathrm{B}$ & $12.1 \%$ & $\mathbf{( 5 9 )}$ & $18.2 \%$ & $\mathbf{( 7 1 )}$ & $20.1 \%$ & $\mathbf{( 8 4 )}$ \\
\hline $\mathrm{B}-\mathrm{A}$ & $20.2 \%$ & $\mathbf{( 9 9 )}$ & $26.4 \%$ & $\mathbf{( 1 0 3 )}$ & $26.0 \%$ & $\mathbf{( 1 0 8 )}$ \\
\hline $\mathrm{B}-\mathrm{B}$ & $60.1 \%$ & $\mathbf{( 2 9 4 )}$ & $48.2 \%$ & $\mathbf{( 1 8 8 )}$ & $45.0 \%$ & $\mathbf{( 1 8 7 )}$ \\
\hline
\end{tabular}

Table 4. Syllable Structure: first-last letter patterns

\section{Questionnaire Results}

The overall results are summarised below in Table 5 .

\begin{tabular}{|c|c|c|c|c|c|c|}
\hline & \multicolumn{2}{|c|}{$\frac{\text { Search Engines }}{63 \text { responses }}$} & \multicolumn{2}{|c|}{$\frac{\text { Subject gateways/portals }}{18 \text { responses }}$} & \multicolumn{2}{|c|}{$\begin{array}{l}\text { Databases } \\
35 \text { responses }\end{array}$} \\
\hline \multicolumn{7}{|l|}{$\begin{array}{l}\text { 1. Brand Names picked which } \\
\text { employed the most frequently } \\
\text { occurring characteristics }\end{array}$} \\
\hline Conveyed no service information & $12.7 \%$ & (8) & $28.0 \%$ & (5) & $42.9 \%$ & (15) \\
\hline Used existing words & $74.6 \%$ & (47) & $50.0 \%$ & (9) & $80.0 \%$ & (28) \\
\hline No Alliteration & $66.7 \%$ & (42) & $72.2 \%$ & (13) & $65.7 \%$ & (23) \\
\hline Average word length (mode) & $39.7 \%$ & (25) & $22.2 \%$ & (4) & $37.1 \%$ & (13) \\
\hline B-B Syllable structure & $73.0 \%$ & (46) & $72.2 \%$ & (13) & $25.7 \%$ & (9) \\
\hline No Plosives & $16.0 \%$ & (10) & $22.2 \%$ & (4) & $28.6 \%$ & (10) \\
\hline \multicolumn{7}{|l|}{$\begin{array}{l}\text { 2. Brand Names picked which did } \\
\text { not employ the most frequently } \\
\text { occurring characteristics }\end{array}$} \\
\hline Conveyed direct service information & $87.3 \%$ & (55) & $72.2 \%$ & (13) & $57.1 \%$ & (20) \\
\hline Used concocted words & $25.4 \%$ & (16) & $50.0 \%$ & (9) & $17.1 \%$ & (6) \\
\hline Use of Alliteration & $33.3 \%$ & (21) & $28.0 \%$ & (5) & $34.3 \%$ & (12) \\
\hline Non average word length & $58.7 \%$ & (37) & $72.2 \%$ & (13) & $62.9 \%$ & (22) \\
\hline A-A Syllable structure & $27.0 \%$ & (17) & $28.0 \%$ & (5) & $71.4 \%$ & (25) \\
\hline Use of Plosives & $84.1 \%$ & (53) & $78.0 \%$ & (14) & $71.4 \%$ & (25) \\
\hline
\end{tabular}


Table 5. Questionnaire results

Some of the figures may not add up to a total of $100 \%$. This was because a few respondents felt that they were unable to pick the brand names which they preferred the most out of the pairs of two. They had never heard of the brand names before and were therefore unable to comment on the ones they preferred.

As noted earlier, search engines tended to convey far less service information than both online databases and subject gateways/portals. Overall, it was found that brand names tended not to convey any information about the service at all. In contrast to this, respondents to the questionnaires tended to prefer the brand names which conveyed direct information about the service and these differences were found to be significant at the $\mathrm{p} \leq 0.005$ level.

Respondents tended to prefer the brand names which used existing words as opposed to concocted words. However, for subject gateways/portals, there was an even split between these two variables and the differences across all three service categories were only found to be significant at the $\mathrm{p} \leq 0.050$ level.

The individual analysis of the brand names showed that phonetic structure (i.e., the use of alliteration, assonance, consonance and onomatopoeia) was not a very common feature for any of the three service categories. Out of these phonetic devices, however, alliteration occurred the most. Therefore, the use of alliteration was tested in the three questionnaires. Respondents tended to prefer the brand names which did not make use of alliteration. However, this difference was not statistically significant.

The questionnaire analysis showed that respondents tended not to prefer the brand names which comprised of the most frequently occurring letter lengths (as ascertained by the individual analysis). However, this preference was not statistically significant. 
Both the search engines and subject gateways/portals brand names which employed the consonant-consonant syllable structure pattern were preferred by respondents. In contrast to this, however, the vowel-vowel syllable structure pattern was preferred for database brand names.

Respondents tended not to prefer the brand names which employed plosives, but the difference between the three categories of information service was not statistically significant.

The questionnaires also asked respondents to indicate whether they were male or female. Although there were no statistically significant differences between gender and choice of answers, it was found that on two occasions, males and females preferred the complete opposites of one another. For the search engine questionnaire, item number four included the pair of brand names: Pro Fusion and Eye on the web. This pair of brand names was testing the mode average letter length of brand names for search engines. The mode letter length was found to be nine letters (comprising two words). Although the letter length of the brand name was found to be of no real significance, it was found that $64 \%$ of males preferred the name Pro Fusion, compared to only $24 \%$ of females. We feel that this difference was possibly due to the nature of the words themselves. It is possible that this brand name may have been preferred by males due to the meaning of the word 'fusion' and its somewhat 'masculine' connotations. An interesting point to consider when creating brand names for information services is that there is the possibility that some words are likely to appeal more to one gender than the other.

For the database questionnaire, the pair of brand names, IPO Central and The Budget Database also created contrasting male/female responses. $80 \%$ of males picked The Budget Database compared to only $48 \%$ of females. We feel that this difference is possibly due to the subject nature of the brand name (i.e., budget/money). 


\section{Discussion}

In comparing these two sets of results, it is clear that there are a number of notable differences.

The analysis of names demonstrated that search engines tended to convey far less service information than both online databases and subject gateways/portals. Overall, it was found that brand names tended not to convey any information about the service at all. In contrast, respondents to the questionnaires preferred the brand names which conveyed direct information about the service.

The brand names across all three service categories used existing words far more than concocted words. the results from the questionnaires showed a similar, but not so strong preference for real words.

Phonetic structure (i.e., the use of alliteration, assonance, consonance and onomatopoeia) was not a very common feature for any of the three service categories. The questionnaires looked at the use of alliteration and it was found that respondents tended to prefer the brand names which did not make use of this linguistic device. However, this preference was not statistically significant. Respondents tended not to prefer brand names which were comprised of the most frequently occurring letter lengths. However, this preference was not statistically significant.

In support of the individual analysis, both the search engines and subject gateways/portals brand names which employed the consonant-consonant syllable structure pattern were preferred by respondents, and this preference was found to be statistically significant.

Respondents tended not to prefer the brand names which employed plosives. However, this preference was not statistically significant. 
Out of the six criteria which the questionnaires looked at, only two were found to statistically support the results from the brand name analysis. It could be said that some of the desired brand name characteristics as set out in the literature are out of date and no longer represent what people like to see in a brand name.

Although the sample of people who filled in the questionnaires were familiar with using online information services, they did not constitute a representative sample as they were all staff and students from the University of Loughborough. In addition, there was a 22\% return rate on the questionnaires. Although this was a good response rate for an unsolicited questionnaire, the sample was quite small.

On two occasions, males and females preferred the complete opposites of one another. These differences are possibly due to the connotations that the brand names have. This is an important point to consider when creating brand names for information services. Whilst the information profession is well known as being predominantly female, it may be that the senior management who make decisions are predominantly male. It is therefore important to consider who the actual users of an information service will be, in relation to words which will appeal more to one gender than the other.

It is also possible that the subject nature of the brand names may have distorted the results slightly. For the database questionnaire, the pair of brand names, IPO Central and The Budget Database, there was also quite an interesting male/female response. $80 \%$ of males picked The Budget Database compared to only $48 \%$ of females. This difference is possibly due to the subject nature of the brand name (i.e., budget/money). It is possible that this subject appealed more to the men who answered the online database questionnaire than the women, rather than it being a true indication of 'brand name' preference as opposed to subject preference. This could also be true for other brand names included in the questionnaire that conveyed service information (e.g., Scholarly Sports Sites, Science Direct, Town Focus). Although respondents were instructed to pick brand names that they would be most attracted to use if looking for information on a topic in general, as opposed to topics they were interested in, this was a 
variable that could not be controlled. Respondents were obviously likely to be attracted to certain brand names if they indicated that they were for an information service that the respondent was interested in.

Search engines tended to convey far less service information than both online databases and subject gateways/portals. A likely reason for this is that both online databases and gateways/portals are generally related to one specific subject, whereas search engines look for information on a multitude of different subjects.

As the brand names that were used in this investigation were all genuine brand names, it is possible that people taking part in the questionnaires may have recognised some of the brand names that were used. People could possibly then have been drawn to pick (or not pick) those brand names because of existing positive or negative associations. We tried to control this by using names that were thought to be less well-known. As a result of trying to include the lesser known brand names in the questionnaires, a further problem occurred. Three respondents to the questionnaires stated that they were unable to pick the brand names that they preferred as they had never heard of the brand names before and were therefore unable to comment on the ones they preferred.

A further two respondents stated that they were unable to give a preference for the pair of brand names, Byte Search and What u seek, which featured in the search engine questionnaire. They thought (incorrectly) that the brand name What u seek, had been misspelled by the experimenter, and that they were therefore unable to comment on whether or not they liked the brand name. Many search engine brand names adopt this form of informal language, e.g., 4u2find, 2 look 4 it, Click thru network, Subjex.com. This 'new' form of language is increasingly popular with young people, especially since text messaging has become so popular (Crystal, 2001). It is likely that brand name creators bear this in mind when creating names for services. Search engines are much more likely to be aimed at young people than subject gateways/portals, and this is a possible reason why search engine brand names contained many examples of this informal use of language. Although this approach may appeal to some users of search 
engines, it is not likely to appeal to everyone. The use of informal language in brand names may dissuade some people from using the service as it can communicate a lack of professionalism. . However, it is less likely that a user would question the spelling or use of language in a brand name if they saw it online as opposed to in a questionnaire.

\section{Comparison with the Myers et al work}

In 1979, Myers et al carried out a study which looked at the characteristics of brand names used in marketing information products and services (Myers et al., 1979). They found that the brand names studied tended to employ meaningless concocted words and that the favoured words began and ended with a consonant. Computerised information systems and online databases tended to employ nouns far more than adjectives, and that in contrast, microfilm readers were far more likely to employ brand names which conveyed product information or atmosphere.

In contrast, this investigation found that for all three service categories, existing words were used for brand names far more than concocted words. These existing words tended to convey far more service information for both online databases and subject gateways/portals than search engines. A possible reason for the much higher proportion of service information which is conveyed now as opposed to in 1979 is the fact there are more online information services in existence now. Users of information services often need to search for information quickly and efficiently in order to meet work deadlines. This requires that users are able to rapidly distinguish the information services which will be of most value to them.

\section{Conclusions}

How much attention those who promote electronic information services will pay to the analysis of brand name characteristics and their effectiveness depends on the importance they attach to the marketing of their service. There are several possible approaches which practitioners can take. The aggressive approach aims to sharply differentiate a 
service from similar services in the minds of users. The defensive approach would be to adopt a 'me too' attitude towards branding. This involves seeking to be perceived as similar to other services. The third approach is that, 'professional life is too busy for marketing approaches - which in practice often means a non-aggressive differentiation of the service from successful services' (Myers et al., 1979). We leave it to those who develop brand names to decide which approach they should adopt. However, we would like to suggest three frameworks for the future branding of online information services.

\section{Search engines}

- Adopt a brand name which conveys 'service atmosphere' rather than direct service information (e.g., use verb combinations to reflect the act of searching for information, 'Surf N Search', 'Infoseek’).

- $\quad$ Use existing words, such as, nouns/adjectives, as opposed to concocted ones.

- Search engine design allows for use of 'informal language'. However, this needs to be considered carefully in relation to both the intended target market of the service, and the quality of the service.

- Only make use of linguistic devices when the service explicitly lends itself to one of these techniques, as opposed to creating a brand to 'fit around' the service.

(Linguistic devices would include the use of alliteration, assonance, onomatopoeia and plosives.)

- A short brand name consisting of two or less words tends to be the most memorable.

- The promoters of the service should also seek to enhance 'symbolic aspects' by developing an image, a logo, a house style, and a 'first screen' which makes use of an effective design theme which emphasises the unique qualities of the service.

\section{Subject gateways/portals}

- Adopt a brand name which conveys direct service information in order to differentiate the service from those of a similar subject nature.

- Use existing words as opposed to concocted ones, (e.g., nouns, adjectives). 
- Subject gateways and portals specifically lends itself to the construction of acronyms as effective brand names.

- Only make use of linguistic devices when the service explicitly lends itself to one of these techniques as opposed to creating a brand to 'fit around' the service. Linguistic devices would include the use of alliteration, assonance, onomatopoeia and plosives.

- The promoters of the service should also seek to enhance 'symbolic aspects' by developing an image, a logo, a house style, and a 'first screen' which makes use of an effective design theme which emphasises the unique qualities of the service.

\section{Online databases}

- Adopt a brand name which conveys direct service information in order to differentiate the service from those of a similar subject nature.

- Use existing words as opposed to concocted ones, (e.g., nouns, adjectives).

- Use acronyms as effective brand names.

- Only make use of linguistic devices when the service explicitly lends itself to one of these techniques as opposed to creating a brand to 'fit around' the service.

\section{New research areas}

An area which was briefly touched upon in this investigation was the symbolic aspects of a service. It was suggested that since intangible factors are more pronounced in services, branding them involves careful handling of symbolic aspects. In relation to this, and to subject gateways/portals and online databases in particular, the 'first screen' of an online site is no doubt crucial in encouraging users to spend further time browsing. In light of this, it would be interesting to investigate brand name creation and effectiveness in conjunction with the actual design and layout elements of a site's 'first screen'. This would involve consideration of characteristics such as, images, font style, colour, shapes, date, overall layout and 'house style'. 
The issue of gender preferences within brand name selection was touched upon slightly in this investigation. It would be interesting to explore these gender differences in more detail.

\section{References}

\section{EN.REFLIST}

